\title{
Normosmic idiopathic hypogonadotropic hypogonadism due to a novel GNRH1 variant in two siblings
}

\author{
Satyanarayana V Sagi1, Hareesh Joshi¹, Emily Whiles', Mondy Hikmat1, Vijith R Puthi², Jane MacDougall3, \\ Sarah L Spiden ${ }^{4}$, Gavin Fuller ${ }^{4}$, Soo-Mi Park 5 and Samson O Oyibo ${ }^{1}$
}

1Department of Diabetes and Endocrinology, Peterborough City Hospital, Peterborough, UK, 2Department of Paediatrics, Peterborough City Hospital, Peterborough, UK, ${ }^{3}$ Department of Reproductive Medicine, Cambridge University Hospitals NHS Foundation Trust, Cambridge, UK, ${ }^{2}$ East Midlands and East of England NHS Genomic Laboratory Hub, Cambridge University Hospital NHS Foundation Trust, Cambridge Biomedical Campus, Cambridge UK, and ${ }^{5}$ Department of Clinical Genetics Service, Cambridge University Hospital NHS Foundation Trust, Cambridge, UK

\author{
Correspondence \\ should be addressed \\ to S Oyibo \\ Email \\ samoyibo@yahoo.co.uk
}

\section{Summary}

Hypogonadotropic hypogonadism is characterised by insufficient secretion of pituitary gonadotropins resulting in delayed puberty, anovulation and azoospermia. When hypogonadotropic hypogonadism occurs in the absence of structural or functional lesions of the hypothalamic or pituitary gland, the hypogonadism is defined as idiopathic hypogonadotropic hypogonadism $(\mathrm{IHH})$. This is a rare genetic disorder caused by a defect in the secretion of gonadotropin releasing hormone (GNRH) by the hypothalamus or a defect in the action of GNRH on the pituitary gland. Up to $50 \%$ of IHH cases have identifiable pathogenic variants in the currently known genes. Pathogenic variants in the GNRHR gene encoding the GNRH receptor are a relatively common cause of normosmic IHH, but reports of pathogenic variants in GNRH1 encoding GNRH are exceedingly rare. We present a case of two siblings born to consanguineous parents who were found to have normosmic idiopathic hypogonadotropic hypogonadism due to homozygosity of a novel loss-of function variant in GNRH1. Case 1 is a male who presented at the age of 17 years with delayed puberty and under-virilised genitalia. Case 2 is a female who presented at the age of 16 years with delayed puberty and primary amenorrhea.

\section{Learning points:}

- $\mathrm{IHH}$ is a genetically heterogeneous disorder which can be caused by pathogenic variants affecting proteins involved in the pulsatile gonadotropin-releasing hormone release, action, or both.

- Currently known genetic defects account for up to $50 \%$ of all $\mathrm{IHH}$ cases.

- GNRH1 pathogenic variants are a rare cause of normosmic IHH.

- $\mathrm{IHH}$ is associated with a wide spectrum of clinical manifestations.

- IHH can be challenging to diagnose, particularly when attempting to differentiate it from constitutional delay of puberty.

- Early diagnosis and gonadotrophin therapy can prevent negative physical sequelae and mitigate psychological distress with the restoration of puberty and fertility in affected individuals. 


\section{Background}

Hypogonadotropic hypogonadism is characterised by low levels of testosterone or oestradiol in the presence of impaired or defective secretion of luteinizing (LH) and follicle stimulating hormone ( $\mathrm{FSH}$ ) from the pituitary gland. In the absence of any anatomical or functional lesions of the pituitary or hypothalamic gland, the hypogonadotropic hypogonadism is referred to as idiopathic hypogonadotropic hypogonadism (IHH).

The defect in the synthesis and secretion of pituitary hormones is intricately linked to the release and action of gonadotropin releasing hormone (GNRH) from the hypothalamus. GNRH is the central regulator in reproductive function and sexual development. The secretion of GNRH is pulsatile in nature, being suppressed in childhood and activated with progression into and through puberty. The key factors responsible for successful pulse-generator activation of sexual development are the frequency and amplitude of the GNRH pulses. The failure to activate pulsatile secretion leads to hypogonadotropic hypogonadism (1). The clinical manifestations can range from incomplete or failure to go through puberty, cryptorchidism, micropenis, and infertility in males to primary amenorrhea, failure to go through puberty, growth retardation, and infertility in females. Osteoporosis can result from untreated hypogonadism, and bimanual synkinesis (mirror movements) has also been reported in some individuals. Syndromic IHH, such as those caused by pathogenic variants in the FGFR1 gene, can be associated with dysmorphic and other clinical features such as hypodontia, cleft lip and palate, and digital anomalies such as syndactyly and ectrodactyly are other clinical manifestations.

Idiopathic hypogonadotropic hypogonadism with normal sense of smell (normosmic IHH) or with hypoosmia or anosmia (Kallman syndrome) is a complex and rare disorder characterised by insufficient GNRH neuronal action on an otherwise normal hypothalamo-pituitarygonadal axis. This could be due to defective development or migration of GNRH neurones, impaired secretion of GNRH from neurons, disrupted interaction between the GNRH ligand and its receptor, or impaired secretion of LH and FSH $(2,3)$. To date, pathogenic variants in around 50 genes have been reported to cause IHH which account for up to $50 \%$ of IHH cases, suggesting that further genes remain to be discovered (4). IHH has an incidence of 1-10 in 100,000 live births with a variable mode of inheritance and five-fold male predominance (2).

Kallman syndrome is genetically heterogeneous: the ANOS1 gene has been implicated in $10-20 \%$ of cases.
Normosomic IHH is also genetically heterogeneous, of which pathogenic variants in GNRHR and TACR3 are the most frequent cause (in two-thirds of variants detected) (4). We report a rare case of normosmic IHH in two siblings from a consanguineous family caused by homozygosity for a novel frameshift likely pathogenic variant in the GNRH1 gene.

\section{Case presentation}

\section{Case 1}

Medical history and demographics

A 17-year-old male presented with a history of delayed puberty. He was born to healthy second-cousin parents of Pakistani origin from a family with multiple consanguineous relationships. Two paternal aunts were said to be infertile. He did not report any headache or visual disturbances. His sense of smell was intact. He was born 3 months prematurely by caesarean section. The patient had normal development and growth with no learning difficulties. He was not allergic to any medications. On examination, he was found to be overweight with a weight of $86.4 \mathrm{~kg}$ (BMI of 27.3) and height of $178 \mathrm{~cm}$ (50th percentile). Mid-parental target height (based on maternal height of $162 \mathrm{~cm}$ and paternal height of 185 $\mathrm{cm}$ ) was $172-189 \mathrm{~cm}$. His right testis was small and his left testis was not palpable. He had hypoplastic scrotum, micro-penis, and bilateral gynaecomastia.

\section{Investigation}

The results of the baseline blood tests with normal reference levels are shown in Table 1. Results demonstrated low testosterone and oestradiol levels with inappropriately low gonadotrophin levels consistent with hypogonadotropic hypogonadism. Gonadotropin releasing hormone stimulation test illustrated low testosterone levels and no elevation of basal gonadotropins levels. Ultrasound of the testes revealed small avascular testes (right testis measuring $11.2 \mathrm{~mm}$ x $6.5 \mathrm{~mm}$ x $10.8 \mathrm{~mm}$; left testis measuring 13.2 $\mathrm{mm} \times 5.7 \mathrm{~mm} \times 6.8 \mathrm{~mm}$ ). The corresponding testicular volumes were $0.56 \mathrm{~mL}$ and $0.36 \mathrm{~mL}$, respectively. An MRI pituitary contrast scan showed a pituitary gland of normal size and appearance. A bone density scan revealed a low for age value in the lumbar spine (z-score of -2.5 S.D., $0.766 \mathrm{~g} / \mathrm{cm}^{2}$ ) and neck of femur (z-score of -1.7 s.D., $\left.0.795 \mathrm{~g} / \mathrm{cm}^{2}\right)$. Subsequent chromosomal analysis revealed $46 \mathrm{XY}$ karyotype.

Next Generation Sequencing (NGS) of the coding region (+/-5 bp) of the following genes (reference sequences) using the Illumina TruSight One sequencing panel was 
Table 1 Baseline blood results for both patients with laboratory reference ranges.

\begin{tabular}{|c|c|c|c|}
\hline Endocrine test & Reference range & $\begin{array}{c}\text { Case } 1 \\
(\mathrm{M})\end{array}$ & $\begin{array}{c}\text { Case } 2 \\
(\mathrm{~F})\end{array}$ \\
\hline $\begin{array}{l}\text { Testosterone, } \\
\mathrm{nmol} / \mathrm{L}\end{array}$ & $10-38 \mathrm{nmol} / \mathrm{L}$ & 0.3 & - \\
\hline Oestradiol, pmol/L & $100-750 \mathrm{pmol} / \mathrm{L}$ & - & $<37$ \\
\hline Prolactin, mU/L & $<500 \mathrm{mU} / \mathrm{L}$ & 144 & 217 \\
\hline LH, U/L (basal) & $1-9 \mathrm{U} / \mathrm{L}$ & $<1$ & $<1$ \\
\hline FSH , U/L (basal) & $1-14 U / L$ & $<1$ & $<1$ \\
\hline \multicolumn{4}{|l|}{ 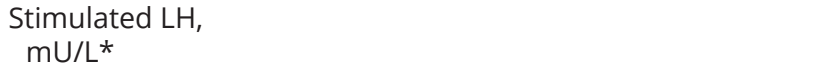 } \\
\hline $20 \min$ & M: 13-58; F: 15-42 & $<1$ & $<1$ \\
\hline $60 \min$ & M: 11-48; F: 12-35 & $<1$ & $<1$ \\
\hline \multicolumn{4}{|l|}{$\begin{array}{l}\text { Stimulated FSH, } \\
\mathrm{mU} / \mathrm{L}^{*}\end{array}$} \\
\hline $20 \min$ & M: 1-7; F: 1-11 & $<1$ & $<1$ \\
\hline $60 \min$ & M: 1-5; F: 1-25 & 1 & 1 \\
\hline $\begin{array}{l}\text { Free thyroxine, } \\
\mathrm{pmol} / \mathrm{L}\end{array}$ & $12-22 \mathrm{pmol} / \mathrm{L}$ & 13.1 & 13.5 \\
\hline $\mathrm{TSH}, \mathrm{mU} / \mathrm{L}$ & $0.3-4.2 \mathrm{mU} / \mathrm{L}$ & 2.42 & 1.30 \\
\hline Sodium, mmol/L & 133-146 mmol/L & 140 & 140 \\
\hline Potassium, mmol/L & $3.5-5.3 \mathrm{mmol} / \mathrm{L}$ & 4.1 & 4.3 \\
\hline Haemoglobin, g/L & $\begin{array}{c}M: 130-180 \\
F: 115-165\end{array}$ & 146 & 132 \\
\hline Haematocrit & $\begin{array}{r}\text { M: } 0.400-0.530 \\
\text { F: } 0.360-0.460\end{array}$ & 0.424 & 0.387 \\
\hline
\end{tabular}

*After an i.v. injection of gonadotrophin-releasing hormone (Gonadorelin $100 \mu \mathrm{g})$ as part of the GNRH stimulation test

$\mathrm{F}$, female; $\mathrm{FSH}$, follicle stimulating hormone; $\mathrm{LH}$, luteinizing hormone; $\mathrm{M}$, male; TSH, thyroid stimulating hormone.

arranged: CHD7 (NM_017780.3); FGF8 (NM_033163.3); FGFR1 (NM_001174067.1); GNRH1 (NM_000825.3); GNRHR (NM_000406.2); KAL1 (NM_000216.2); KISS1 (NM_002256.3); KISS1R (NM_032551.4); $\quad$ PROK2 (NM_001126128.1); PROKR2 (NM_144773.2); TAC3 (NM_013251.3); and TACR3 (NM_001059.2). Additionally, $97.73 \%$ of the target sequence within this panel was sequenced to a depth of 20 fold or more, with analytical sensitivity of $98.3 \%-100 \% \quad(95 \% \quad C I)$. An apparent homozygous likely pathogenic variant in the GNRH1 gene was detected and confirmed via Sanger sequencing: (NM_000825.3 (GNRH1-v001):c.119_122dupGAGA p.(Asp37GlufsTer8)). This is demonstrated in Fig. 1.

This GNRH1 variant is considered extremely rare as it is absent from known disease database (ClinVar and Human Gene Mutation Database (HGMD)) and the population frequency database (Genome Aggregation Database (GnomAD)). The c.119_122dup GNRH1 variant leads to the insertion of a GAGA tetra-nucleotide, which alters the reading frame of the protein and leads to a premature STOP codon in the GNRH1 gene. This is predicted to cause loss of normal protein function either through protein truncation or nonsense-mediated mRNA decay. Other small deletions and insertions, which are similarly predicted to shift the reading frame and result in a premature STOP codon, have been reported as pathogenic in association with hypogonadotropic hypogonadism.

Subsequently, the parents of these siblings were tested for the familial likely pathogenic c.119_122dup GNRH1 variant and each shown to be heterozygous. This confirms bi-parental inheritance of the likely pathogenic c.119_122dup p.(Asp41GlufsTer8) GNRH1 variant in the affected siblings and is consistent with a diagnosis of autosomal recessive IHH in this family.

\section{Treatment}

The patient was started on an i.m. injection of testosterone (Sustanon $50 \mathrm{mg}$ ) once every 4 weeks with a gradual increase in dose. He was also started on calcium and vitamin D supplements and advised to maintain a healthy lifestyle with regular exercise.

\section{Outcome and Follow-up}

The patient's testosterone levels improved with hormone replacement therapy. He has shown progression with sexual development and is being regularly followed up in the Endocrine clinic. The patient has received counselling concerning infertility.

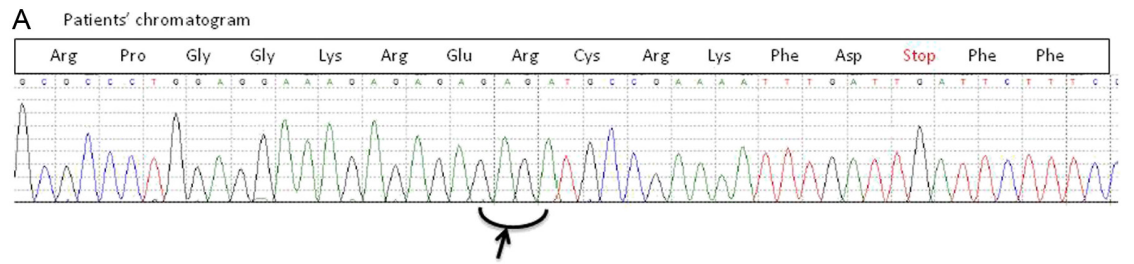

B Reference chromatogram

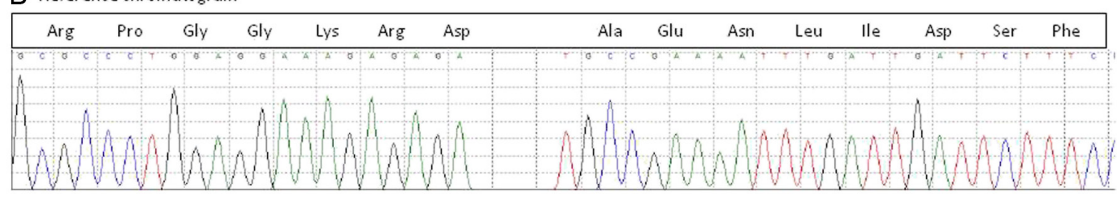

\section{Figure 1}

Chromatogram of the Sanger sequencing. (A) Patients' chromatogram showing the duplicated tetra-nucleotide base (arrow) and glutamate (Glu) replacing the wild-type aspartate (Asp) at position 37 and the STOP 8 amino acids downstream. (B) Normal reference chromatogram. 


\section{Case 2}

\section{Medical history and demographics}

A 16-year-old female (sibling to case 1) presented with a history of delayed puberty and primary amenorrhoea. She had no headaches or visual disturbance. She was born at term by normal vaginal delivery. She had a cleft palate at birth which was repaired with no adverse effect on speech and feeding. On examination, she had a weight of $53.5 \mathrm{~kg}$ (BMI of 20.9) and height of $160 \mathrm{~cm} \mathrm{(30th}$ percentile). Mid-parental target height was 159-176 cm. She had hyperpigmented linear rashes over her arms and chest (thought to be a lichenoid reaction). She had chest adiposity, but breast buds were difficult to palpate. Her axillary hair was Tanner stage 1 and pubic hair Tanner stage 2 . She reported a normal sense of smell.

\section{Investigation}

The results of the baseline blood tests with normal reference levels are shown in Table 1. Results demonstrated low estradiol levels with inappropriately low gonadotropin levels consistent with hypogonadotropic hypogonadism. Gonadotropin releasing hormone stimulation test produced no elevation of basal gonadotropins. Ultrasound of the pelvis demonstrated a small infantile uterus measuring $3.5 \mathrm{~cm} \times 1.2 \mathrm{~cm} \times 1.9 \mathrm{~cm}$; both ovaries were not demonstrated due to bowel shadowing, and endometrial lining was not visible. An MRI pituitary contrast scan showed a pituitary gland of normal size and appearance. A bone density scan revealed levels in the lower end of the normal range for age in the lumbar spine (z-score of -1.2 s.D., $0.842 \mathrm{~g} / \mathrm{cm}^{2}$ ) and neck of femur (z-score of -1.5 s.D., $\left.0.70 \mathrm{~g} / \mathrm{cm}^{2}\right)$. Subsequent chromosomal analysis revealed a $46 \mathrm{XX}$ karyotype. She was tested for the familial GNRH1 variant detected in her brother and was confirmed as being homozygous for the same variant (NM_000825.3 (GNRH1-v001):c.119_122dupGAGA p.(Asp37GlufsTer8)).

\section{Treatment}

The patient was started on a pubertal induction regimen with ethinyl estradiol $2 \mu \mathrm{g}$ daily. The dose was increased by $2 \mu \mathrm{g}$ every six months. She progressed through puberty well and had break-through vaginal bleeding on a dose of $12 \mu \mathrm{g}$ daily. At this stage, her treatment was changed to the combined oral contraceptive pill (Loestrin 20) to induce regular withdrawal bleeding.

\section{Outcome and follow-up}

The patient had progression in terms of puberty (breast: stage $2-3$, pubic hair: stage $2-3$, axillary hair: stage 1 ).
She was counselled about fertility and is being regularly followed up in the Gynaecological Endocrine clinic.

\section{Discussion}

Idiopathic hypogonadotropic hypogonadism (IHH) is a complex genetic disorder that is characterised by genetic heterogeneity, variable expression, penetrance, and modes of inheritance. Classically, IHH has been categorized into two distinct clinical entities: Kallmann syndrome and normosmic IHH. IHH can also be syndromic. More recently, it has been noted that the $\mathrm{IHH}$ phenotype is variable, partially due to oligo-genic mode of inheritance and gene-environment interactions $(1,2)$.

The GNRH1 (OMIM number 614841) gene is located on the short arm of chromosome 8 at position 21.2. It encodes a preproprotein (progonadoliberin-1, proGNRH1), which after proteolytic splicing releases the active decapeptide GNRH1 and the GNRH-associated peptide. The decapeptide GNRH1 triggers the release of luteinizing hormone and follicle stimulating hormone from the pituitary gland. The GNRH1 gene is expressed in a select population of hypothalamic neurones and a defect results in hypogonadotropic hypogonadism.

Pathogenic variants have been reported in many different genes in patients with $\mathrm{IHH}$, but those in one of the most obvious candidate gene, GNRH1, have rarely been reported. In a study involving 310 patients with normosmic idiopathic hypogonadotropic hypogonadism (normosmic IHH), five patients were identified with rare bi-allelic variants in GNRH1 consisting of missense, nonsense, and frameshift variants (5). In another cohort of 130 unrelated patients with $\mathrm{IHH}$, a novel homozygous splice site variant was detected in GNRH1 in a single case (6). Another case of normosmic IHH due to a single nucleotide insertion resulting in a frameshift variant in the GNRH1 gene was identified in a brother and sister of non-consanguineous parents of Romanian origin (7). The clinical consequence of these inactivating variants in the GNRH1 gene is an absence of the intact GNRH1 protein and resultant failure to stimulate gonadotropin release from the pituitary gland.

The diagnosis of $\mathrm{IHH}$ and differentiating it from constitutional delay of puberty can be very challenging. A timely diagnosis and treatment to induce puberty can be beneficial for sexual, bone, and metabolic health and might help minimize some of the psychological effects of this rare condition (8). If patients wish to conceive, ovulation or spermatogenesis can be induced using gonadotrophins. 
We report two siblings with non-syndromic IHH born of a consanguineous union who were found to be homozygous for a novel likely pathogenic frameshift variant in the GNRH1 gene resulting in low gonadotropin levels. Parental testing has confirmed bi-parental inheritance. It is uncertain whether the cleft palate in the female patient is related to IHH, as cleft palate in itself is a relatively common congenital anomaly (affecting 1 in 2500 births) and is not a reported feature in previous cases of GNRH1-related IHH. The autosomal recessive inheritance confirms a recurrence risk of one in four for each future pregnancy for the parents, who are still of reproductive age, and an increased risk to any future consanguineous relationships within the family.

In conclusion, we have presented a case of normosmic IHH in two siblings from a consanguineous family due to a novel frameshift variant in the GNRH1 gene. We hope that this case report not only adds to the existing literature but also contributes to gaining insight into a complex genetic condition.

\section{Declaration of interest}

The authors declare that there is no conflict of interest that could be perceived as prejudicing the impartiality of the research reported.

\section{Funding}

This research did not receive any specific grant from any funding agency in the public, commercial, or not-for-profit sector.

\section{Patient consent}

Written informed consent for publication of their clinical details and/or clinical images was obtained from both patients.

\section{Author contribution statement and acknowledgements}

S V Sagi, E whiles, H Joshi, M Hikmat, V R Puthi, S M Park, J MacDougall, $S$ Spiden, G Fuller, and S O Oyibo were all involved in the writing of this case report and critically revised the final manuscript for submission.
This case was presented in abstract form at the Society for Endocrinology BES 2019 meeting. V R Puthi and S V Sagi identified these cases. S M Park undertook genetic testing in case 1 and the parents after the diagnosis was established in case 2, and J MacDougall manages case 2, and all were the named physicians for the patients.

\section{References}

1 Beate K, Joseph N, Nicolas de R \& Wolfram K Genetics of isolated hypogonadotropic hypogonadism: role of $\mathrm{GnRH}$ receptor and other genes. International Journal of Endocrinology 20122012147893. (https://doi.org/10.1155/2012/147893)

2 Bonomi M, Libri DV, Guizzardi F, Guarducci E, Maiolo E, Pignatti E, Asci R, Persani L \& Idiopathic Central Hypogonadism Study Group of the Italian Societies of Endocrinology and Pediatric Endocrinology and Diabetes New understandings of the genetic basis of isolated idiopathic central hypogonadism. Asian Journal of Andrology 201214 49-56. (https://doi.org/10.1038/aja.2011.68)

3 Chelaghma N, Rajkanna J, Trotman J, Fuller G, Elsey T, Park SM \& Oyibo SO Normosmic idiopathic hypogonadotrophic hypogonadism due to a rare KISS1R gene mutation. Endocrinology, Diabetes and Metabolism Case Reports 20182018 18-0028. (https://doi. org/10.1530/EDM-18-0028)

4 Topaloglu AK Update on the genetics of idiopathic hypogonadotropic hypogonadism. Journal of Clinical Research in Pediatric Endocrinology 20179 113-122. (https://doi.org/10.4274/ jcrpe.2017.S010)

5 Chan YM, de Guillebon A, Lang-Muritano M, Plummer L, Cerrato F, Tsiaras S, Gaspert A, Lavoie HB, Wu CH, Crowley WF, et al. GNRH1 mutations in patients with idiopathic hypogonadotropic hypogonadism. PNAS 2009106 11703-11708. (https://doi. org/10.1073/pnas.0903449106)

6 Amato LGL, Montenegro LR, Lerario AM, Jorge AAL, Guerra Junior G, Schnoll C, Renck AC, Trarbach EB, Costa EMF, Mendonca BB, et al. New genetic findings in a large cohort of congenital hypogonadotropic hypogonadism. European Journal of Endocrinology 2019181 103-119. (https://doi.org/10.1530/ EJE-18-0764)

7 Bouligand J, Ghervan C, Tello JA, Brailly-Tabard S, Salenave S, Chanson P, Lombes M, Millar RP, Guiochon-Mantel A \& Young J Isolated familial hypogonadotropic hypogonadism and a GNRH1 mutation. New England Journal of Medicine 2009360 2742-2748. (https://doi.org/10.1056/NEJMoa0900136)

8 Boehm U, Bouloux PM, Dattani MT, de Roux N, Dodé C, Dunkel L, Dwyer AA, Giacobini P, Hardelin JP, Juul A, et al. Expert consensus document: European Consensus Statement on congenital hypogonadotropic hypogonadism - pathogenesis, diagnosis and treatment. Nature Reviews: Endocrinology 201511 547-564. (https:// doi.org/10.1038/nrendo.2015.112)

Received in final form 5 February 2020

Accepted 14 February 2020 